\title{
Monoclonal Antibodies Reacting with the Exopolysaccharide Xanthan from Xanthomonas campestris
}

\author{
By LARS R. HAAHEIM, ${ }^{*}$ GUNNAR KLEPPE ${ }^{2} \dagger$ AND \\ IAN W. SUTHERLAND ${ }^{3}$ \\ ${ }^{1}$ Department of Microbiology and Immunology, University of Bergen, The Gade Institute, \\ Haukeland Hospital, N-5021 Bergen, Norway \\ ${ }^{2}$ Norsk Bioferm AS, Hanabryggene Technology Center, PO Box 798, Krossen, N-4301 Sandnes, \\ Norway \\ ${ }^{3}$ Department of Microbiology, University of Edinburgh, School of Agriculture, West Mains Road, \\ Edinburgh EH9 $3 J G, U K$
}

(Received 11 August 1988; revised 14 November 1988; accepted 18 November 1988)

\begin{abstract}
We have prepared murine hybridomas secreting monoclonal antibodies against the exopolysaccharide xanthan from Xanthomonas campestris pv. campestris 646 after fusing NSO myeloma cells and spleen cells from BALB/c mice immunized with xanthan. Four hybridomas, secreting antibodies designated $\mathrm{A} 6(\operatorname{IgM} \kappa), \mathrm{B} 3(\operatorname{IgM} \kappa), \mathrm{D} 1(\operatorname{IgM} \kappa)$, and D3 $\left(\operatorname{IgG}_{2 \mathrm{~A}} \kappa\right)$, were selected for further studies. All antibodies reacted with a range of different xanthans. Competition studies using variants of the exopolysaccharide as competitors suggested that specificity was mainly against the side-chain. One of the antibodies (B3) appeared to require the fully acylated side-chain with the pyruvylated terminal mannose as the immunodominant part. The three others were assumed to be directed against the nonsubstituted trisaccharide with the inner mannose-glucuronic acid being immunodominant. None of the antibodies reacted with cellulose (the xanthan backbone). Using immunoblotting techniques on nitrocellulose paper both a mixture of monoclonal antibodies, and also polyclonal ascitic fluid, could detect xanthan quantities of approximately $0 \cdot 1 \mu \mathrm{g}$.
\end{abstract}

\section{INTRODUCTION}

The exopolysaccharide xanthan from Xanthomonas campestris is an interesting carbohydrate polymer, with striking rheological properties which make it useful as a food additive (gelling agent) and also as a potential vehicle in enhanced oil recovery (Sandford \& Baird, 1983; Sutherland \& Ellwood, 1979). It consists of a $\beta 1 \rightarrow 4$ glucose polymer, i.e. a cellulose backbone, with $\beta 1 \rightarrow 3$ substituted trisaccharide side-chains of (mannose- $\beta 1 \rightarrow 4$-glucuronic acid- $\alpha 1 \rightarrow 2-$ mannose- $\beta 1-3$ )- on alternate glucose residues (Jansson et al., 1975). The side-chain is variably acylated. The inner mannose may have an O-6 acetyl group and the terminal mannose a 4,6bound pyruvate ketal. Monoclonal antibodies against this exopolysaccharide could be useful for structural studies, for detection purposes in commercial and agricultural settings, and for serological typing purposes (Yano et al., 1979).

We here report the isolation and some of the properties of murine monoclonal antibodies specific for the side-chain of xanthan from $X$. campestris pv. campestris 646 .

\section{METHODS}

Exopolysaccharides. These were prepared from a number of cultures of Xanthomonas campestris pathovars. Bacteria were grown in $750 \mathrm{ml}$ nitrogen-deficient medium (Sutherland \& Wilkinson, 1965) in 2-litre Erlenmeyer

$†$ Present address: Statoil Biotechnology Unit, PO Box 300, N-4001 Stavanger, Norway.

Abbreviations: ELISA, enzyme-linked immunosorbent assay; DMEM-HAT, Dulbecco's modification of Eagle's medium-hypoxanthine/aminopterin/thymidine. 
Table 1. Molar composition relative to glucose of xanthan-type polysaccharides

\begin{tabular}{|c|c|c|c|}
\hline Strain & Glucose & Mannose & Glucuronic acid \\
\hline X. campestris 646 & $2 \cdot 0$ & 1.89 & 0.94 \\
\hline$X$. campestris $646 \mathrm{DAC}^{*}$ & $2 \cdot 0$ & 1.90 & 0.95 \\
\hline$X$. campestris $646 \mathrm{DP} \dagger$ & $2 \cdot 0$ & $1 \cdot 85$ & 0.93 \\
\hline X. campestris 1128 & $2 \cdot 0$ & $1 \cdot 85$ & 0.99 \\
\hline X. campestris 556 & $2 \cdot 0$ & 1.89 & $1 \cdot 04$ \\
\hline$X$. campestris 61 & $2 \cdot 0$ & $2 \cdot 05$ & 0.92 \\
\hline$X$. campestris BD9 $\ddagger$ & $2 \cdot 0$ & 1.02 & $1 \cdot 01$ \\
\hline Klebsiella $\mathrm{K} 5$ & $1 \cdot 0$ & 1.01 & 0.98 \\
\hline
\end{tabular}

flasks shaken at 300 r.p.m. for $48-72$ h. Bacterial cells were removed by centrifugation at $50000 \mathrm{~g}$ for $1 \mathrm{~h}$ and the exopolysaccharides recovered by precipitation with 2 vols cold $\left(-40^{\circ} \mathrm{C}\right)$ acetone. After thorough washing with acetone, the polysaccharides were dissolved in a small volume of water, and dialysed against tap water followed by distilled water. The dialysed polymers were converted to the $\mathrm{Na}^{+}$form by passage through Amberlite IR 120 resin and subsequently lyophilized. The composition of the polysaccharides was checked by HPLC of the acidhydrolysed material (Kennedy \& Sutherland, 1987). Acetyl and pyruvate contents were measured using microcolorimetric methods (Sutherland, 1984). Similar cultural and analytical procedures were used to prepare the serotype 5 polysaccharide from 'Klebsiella aerogenes' ( $K$. pneumoniae) strain NCTC 5051 (hereafter designated Klebsiella K5). The composition of the different polysaccharides is listed in Table 1.

The percentage content $(\mathrm{w} / \mathrm{w})$ of acetate and pyruvate for the xanthans 1128,556 and 646 was $7 \%$ and $1.7 \%$, $1.1 \%$ and $6.0 \%$, and $4.5 \%$ and $4.4 \%$, respectively (Sutherland, 1987). The chemically deacetylated (DAC) and depyruvylated (DP) xanthan 646 were devoid of the corresponding acyl moiety and contained approximately the same amounts of the other acyl group. The xanthan BD9 comes from an X. campestris 646 mutant, and full details of its isolation and characterization will be published later. Briefly, this exopolysaccharide had only $10 \%$ complete side-chains, with the remaining side-chains terminating in glucuronic acid. Only trace amounts of pyruvate could be detected, and acetate constituted $1 \%$ by weight. The xanthan 61 exopolysaccharide contained two acetyl groups on the internal mannose $(12.8 \%$ by weight) and had only trace amounts of pyruvate.

Oligosaccharides were prepared from xanthan 646 . The polysaccharide was treated with an enzyme preparation from a Bacillus species which contained both endo- $\beta$-glucosidase and xanthan lyase activities (Sutherland, 1982, 1987). The tetrasaccharide (A21), consisting of D-glucose, D-mannose (non-acetylated) and unsaturated uronic acid in the molar ratio $2: 1: 1$, was isolated from the diffusible fraction and purified by preparative paper chromatography (Sutherland, 1987).

Monoclonal antibodies. BALB/c mice were vaccinated by two $200 \mu \mathrm{g}$ intraperitoneal injections of xanthan 646 in saline with a 4 week interval, followed by a similar booster dose 9 weeks after the second dose. Spleen cells were harvested and serum was collected $3 \mathrm{~d}$ after the third injection. Protocols for fusion, selective growth and cloning of hybridomas, and maintenance of hybridomas, were according to standard procedures (Galfre et al., 1977) with in-house modifications (Haaheim \& Lund, 1984), except that we used the non-secretor myeloma line NSO at a spleen : myeloma cell ratio of $3: 1$ and polyethylene glycol $4000(\mathrm{BDH})$ as fusing agent. Cells were plated in four TC 48-well culture plates in selective DMEM-HAT medium and supernatants were initially screened for antibodies against 646 and cellulose 2 weeks post-fusion, using ELISA (see below).

Hybridoma growth was recorded in 156 of the 192 wells (on average three hybridoma colonies per well) and 42 of the wells showed evidence of secretion of antibodies against xanthan, seventeen with antibodies against cellulose and eight wells being positive against both. In this study cells from four wells with vigorous hybridoma growth and the highest antibody activity against xanthan (cellulose-negative) were selected for further studies and cloned twice at limiting dilution. All subsequent work was done with four monoclonal antibodies designated A6, B3, D1 and D3, isotyped as being $\operatorname{IgM} \kappa$ (A6, B3 and D1) and $\operatorname{IgG}_{2 \mathrm{~A}} \kappa$ (D3), using ELISA as described previously (Haaheim \& Lund, 1984). Antibodies from cell culture supernatants from hybridomas prepared in our laboratory secreting antibodies belonging to the IgM $\kappa\left(\mathrm{E} 8 /\right.$ control; anti-oxidized DNA) and $\operatorname{IgG}_{2 \mathrm{~A}} \kappa(\mathrm{B} 2 /$ control; anti-APendonuclease) isotypes served as controls.

Polyclonal antibodies. These were obtained from serum of spleen donor (serum/spleen donor), from unimmunized BALB/c mice (serum/control), and from ascitic fluid of mice immunized in the same way as the spleen donor, subsequently injected intraperitoneally with $0.5 \mathrm{ml}$ pristane $(2,6,10,14$-tetramethylpentadecane, EGA-Chemie, FRG) and $10^{7}$ NSO myeloma cells 1 week and 2 weeks after the third injection, respectively (Lacy \& Voss, 1986). Ascitic fluid was collected during a period of $4 \mathrm{~d}$ starting at day 9 after injection of myeloma cells. 
The total volume collected was $7 \mathrm{ml}$, and after pooling, the fluid was delipidized by Frigen 113-TR-T (Lipoclean, Behring Institute, FRG) according to the manufacturer's instructions and stored in aliquots at $-20^{\circ} \mathrm{C}$. This material is referred to as polyascites.

ELISA. This was done by standard procedures and as described previously (Haaheim \& Lund, 1984), with the following modifications. Except where stated otherwise, all incubation steps with antisera, monoclonal antibodies, class- or subclass-specific sera, and enzyme conjugates, were done at room temperature for $1.5 \mathrm{~h}$. The antigens used as target in immunoplates were sonicated $(20 \mathrm{kHz}, 1 \mathrm{~min})$ stock solutions $\left(600 \mu \mathrm{g} \mathrm{ml} \mathrm{m}^{-1}\right.$ in $0 \cdot 1 \mathrm{M}^{-}$ $\mathrm{NaCl}$ ) of xanthans or cellulose (cellulose powder MN300; Macherey, Nagel \& Co.) made up in 0.01 M-phosphatebuffered saline (PBS), pH 7.2, to a concentration of $20 \mu \mathrm{g} \mathrm{ml}-1$. Dilutions of antibodies were done in PBS containing $0.05 \%$ Tween $20(\mathrm{PBS} / \mathrm{T})$. Antibody values are presented either as absorbance $(A)$ at $492 \mathrm{~nm}$, or percentages of $A_{492}$ values relative to control wells (PBS/T), or matrix scores relative to stated $A_{492}$ reference value. Three different ELISA assays were performed, as follows.

(l) Direct screening by adding $30 \mu \mathrm{l}$ PBS/T followed by $60 \mu \mathrm{l}$ undiluted cell culture supernatants and leaving the immunoplate overnight at $4{ }^{\circ} \mathrm{C}$ before further processing with enzyme-labelled conjugate.

(2) Titratnios of antibodies were done by adding $100 \mu \mathrm{l}$ volumes of serial dilutions of antibody in PBS/T to wells.

(3) Competitive analyses were done by mixing in test tubes graded amounts of competitor in PBS/T with an equal volume of a fixed dilution of antibody in PBS/T, giving an $A_{492}$ of approximately $0.75-1.0$ in an uncompeted assay $(=100 \%)$. After occasional shaking for $\mathrm{I} \mathrm{h}$ at $0{ }^{\circ} \mathrm{C}$ test tubes were incubated overnight at $4{ }^{\circ} \mathrm{C}$. Residual antibody activity was measured by adding $100 \mu \mathrm{l}$ of the mixture to duplicate wells for each concentration of competitor, whereas four replicates were tested for each uncompeted monoclonal antibody.

Dot-blotting. This was performed using a Minifold-Microsample Filtration Manifold (SRC-96, Schleicher \& Schüll). Nitrocellulose paper (Bio-Rad Trans-Blot Transfer Medium, cat. no. 162.0115) was cut to fit the manifold, soaked in PBS for $1 \mathrm{~h}$ and laid on top of a similarly sized and prewetted blotting paper (GB003, Schleicher \& Schüll) before mounting. Two hundred microlitre volumes of 10 -fold dilutions of xanthan preparations in PBS were added to wells under suction. Nitrocellulose paper was then blocked by soaking in $10 \%$ (v/v) foetal calf serum in PBS/T for $30 \mathrm{~min}$. The nitrocellulose paper was cut into four parts, incubated with appropriately diluted antibody in PBS/T (A6 and D3, 1:50; B3, 1:4; D1, 1:100 (pooled monoclonals); serum/control, $1: 100 ;$ serum/spleen donor, $1: 200 ;$ polyascites, $1: 4000$ ). All incubation steps were as for ELISA. The peroxidase substrate was HRP Color Development Reagent (Bio-Rad).

\section{RESULTS AND DISCUSSION}

Initially, several of the wells in the fusion plates had antibodies that reacted with either xanthan 646 or cellulose, or with both. It was not ascertained whether a single hybridoma product could recognize common determinants between cellulose and xanthan, i.e. parts of the glucose backbone, since there were on average three hybrid clones per well. As the object of this work was to isolate xanthan-specific monoclonal antibodies, the pools which also reacted with cellulose were excluded from further studies. None of the four selected monoclonal antibodies gave positive reactions in ELISA using cellulose as target (Table 2).

\section{Potency of antibodies}

Serial dilutions of antibodies were tested in ELISA to assess their potency. From Fig. $1(a)$ it can be seen that the monoclonal antibodies from cell culture supernatants could be diluted approximately 500-fold before reaching the end-point, i.e. the level of PBS/T. The control cell culture fluids E8 and B2 never exceeded background level. The polyclonal antibodies in the form of ascitic fluid or serum from the spleen donor could be diluted approximately 800 -fold and between 8000 - and 16000-fold, respectively, before reaching background levels (Fig. $1 b$ ). The serum from unimmunized $\mathrm{BALB} / \mathrm{c}$ mice gave a weak reaction only at $1: 100$ dilution.

\section{Specificity of antibodies}

With the exception of monoclonal antibody B3, deacetylating xanthan 646 only marginally affected the binding of antibodies, whereas depyruvylation abolished reactivity. The xanthan 61 polysaccharide did not measurably bind antibodies, nor did cellulose. None of the control antibodies, E8/control, B2/control, and serum control from unimmunized BALB/c mice, gave positive reactions. The polyclonal anti-xanthan 646 ascitic fluid (polyascites) and serum from the spleen donor reacted strongly with some preparations but weakly or not at all with others.

In the course of this study we suspected that the binding characteristics of the various 


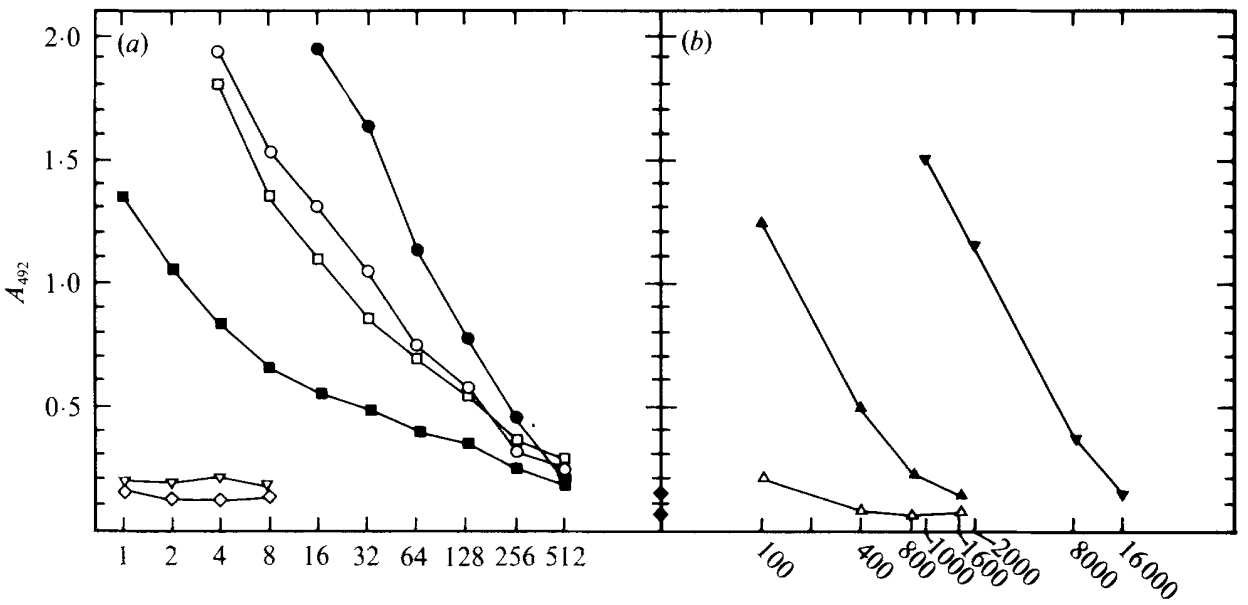

(Dilution of antibody) $)^{-1}$

Fig. 1. Titration of monoclonal antibodies $(a)$ and polyclonal antibodies $(b)$ in ELISA using xanthan 646 as target. $\mathrm{O}, \mathrm{A} 6 ; \mathbf{\square}, \mathrm{B} 3 ; \bullet, \mathrm{D} 1 ; \square, \mathrm{D} 3 ; \diamond, \mathrm{E} 8 /$ control; $\nabla, \mathrm{B} 2 /$ control; $\boldsymbol{\nabla}$, polyascites; $\boldsymbol{\Delta}$, serum/spleen donor; $\triangle$, serum/control; $\bullet$, PBS/T. PBS/T was tested in quadruplicate; the highest and lowest values are shown on the central ordinate. All serum dilutions were tested in duplicate, and ranges (not shown) varied from $\pm 4 \%$ for the lowest dilutions to $\pm 20 \%$ for the highest dilutions.

Table 2. ELISA reactivity of different sources of antibodies in tests with cellulose and various xanthan preparations

All entries are matrix scores relative to an $A_{492}$ value of $2 \cdot 5$. Background values, using PBS/T, gave $A_{492}$ always below 0.120 , i.e. matrix score $=0$. All the antibodies listed gave a matrix score of 0 with cellulose.

\section{B3
A6
D1
D3}

Polyascites

Serum/spleen donor

E8/control

B2/control

Serum/control

\begin{tabular}{|c|c|c|c|c|c|c|}
\hline \multicolumn{7}{|c|}{ Xanthan $\uparrow$ : } \\
\hline & 646 & & BD9 & 556 & 1128 & 61 \\
\hline Native & DP & DAC & & & & \\
\hline 5 & 0 & 2 & 0 & 5 & 1 & 0 \\
\hline 9 & 0 & 8 & 9 & 0 & 0 & 0 \\
\hline 9 & 0 & 9 & 9 & 1 & 0 & 0 \\
\hline 9 & 0 & 8 & 8 & 1 & 0 & 0 \\
\hline 9 & 0 & 9 & $>9$ & 0 & 0 & 0 \\
\hline 5 & 1 & 4 & 8 & 1 & 1 & 0 \\
\hline 0 & ND & ND & ND & 0 & ND & ND \\
\hline 0 & ND & ND & ND & 0 & ND & ND \\
\hline 0 & ND & ND & ND & 0 & ND & ND \\
\hline
\end{tabular}

NA, Not applicable; ND, not determined.

* All monoclonal antibodies were tested as undiluted cell culture supernatants; sera and ascitic fluid were tested at $1: 100$ and $1: 500$ dilution, respectively.

$\dagger$ For xanthan nomenclature, see Methods.

naturally or chemically modified xanthans to the immunoplates was highly variable and/or that structural rearrangements of the xanthans once fixed to the plastic support could interfere with antibody recognition. We therefore performed competitive assays in solution using various xanthans as competitors in tests with monoclonal antibodies, employing native xanthan 646 as target. In no instance could the xanthan 61, or cellulose, inhibit the monoclonal antibodies (data not shown). Xanthan 61 is doubly acetylated on the inner mannose, thus indicating that this mannose residue is critical for antibody recognition.

Monoclonal antibodies A6, DI and D3. These monoclonal antibodies behaved very similarly in all experiments, suggesting that they have similar overall specificity for the trisaccharide side- 


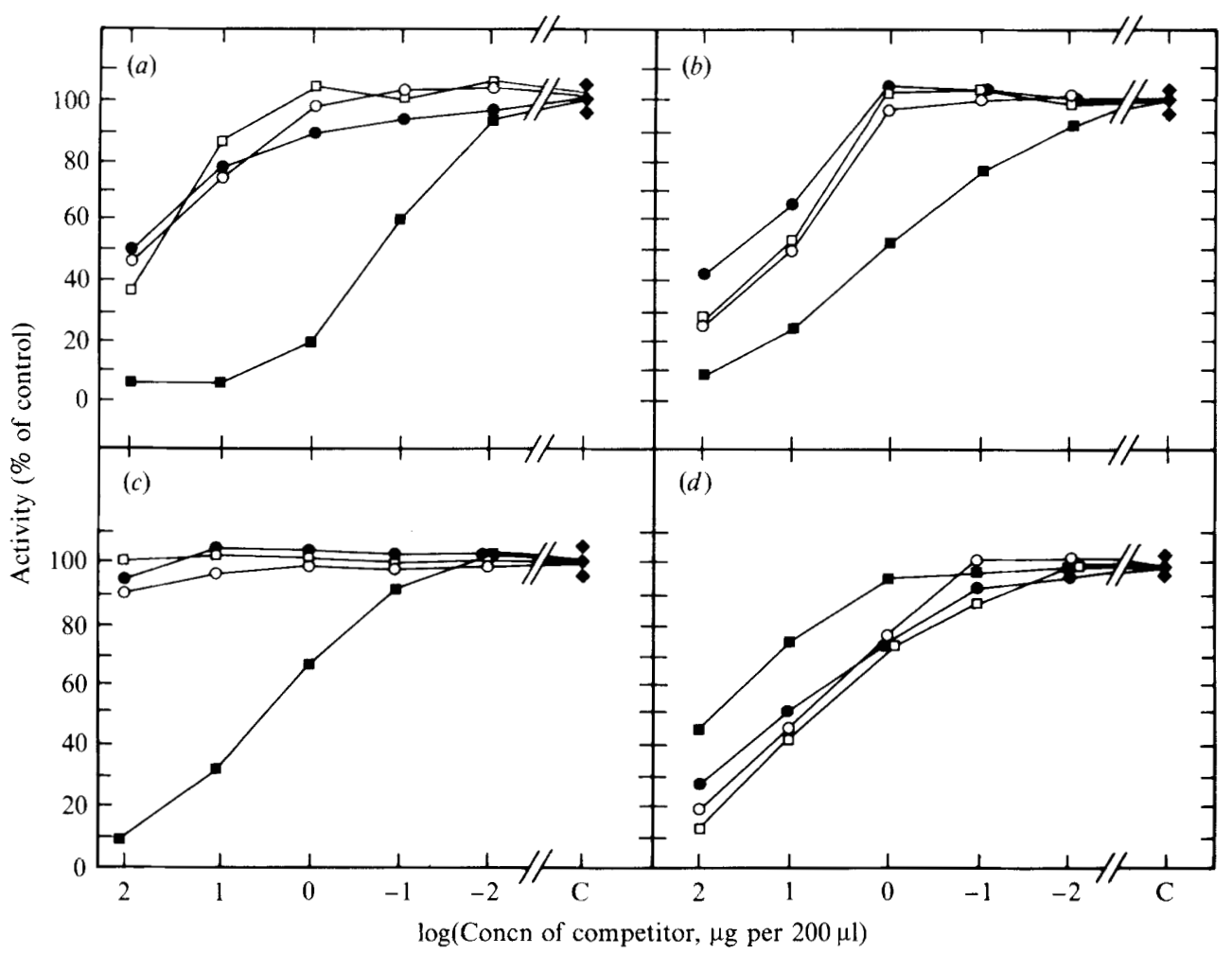

Fig. 2. Representative ELISA competition experiment using monoclonal antibodies in tests with serial dilutions of various xanthans as competitors. Target: xanthan 646. Competitors: xanthan $646(a)$, xanthan $556(b)$, xanthan $1128(c)$, and xanthan BD9 $(d)$. Monoclonal antibodies: $\bigcirc, A 6 ; \mathbf{\square}, \mathrm{B} 3$; D1; $\square$, D3. Each antibody was used at a fixed dilution giving an $A_{492}$ between 0.75 and $1.0(=100 \%)$ in an uncompeted assay (control $=\mathbf{P B S} / \mathrm{T}$ ). All antigen/antibody mixtures were tested in duplicate and are represented in the figure as arithmetic means; ranges (not shown) varied between \pm 4 percentage units (least effective competitor) and \pm 10 percentage units (most effective competitor). The means and ranges for the PBS/T controls (C) are shown in each panel.

chain but without requiring acetate on the inner mannose. This is based on the finding that xanthan 1128 did not inhibit these antibodies and that less xanthan 556 than the homologous xanthan 646 was required for $50 \%$ reduction of antibody activity (Fig. 2, Table 3). Also, chemically deacetylated xanthan 646 was more effective as a blocking agent than native 646, whereas chemically depyruvylated 646 behaved similarly to the native 646 . This could mean that neither pyruvate residue was essential for antibody recognition, which was confirmed by the reaction with $\mathrm{BD} 9$, a polysaccharide with only $10 \%$ intact trisaccharide side-chains, the remaining $90 \%$ having the disaccharide mannose-glucuronic acid. In fact, BD9 was the most effective competitor for these three antibodies, suggesting that the glucuronic acid-inner mannose disaccharide contributes significantly to the epitope.

Although the antibodies A6, D1, and D3 appeared to have the same overall specificity, the reaction patterns given in competition studies with chemically modified xanthan 646 suggest that there may be minor differences in their specificity or affinity for the xanthan epitopes. In fact, the D1 antibody (Fig. 1) showed a titration curve that would suggest a lower affinity (or strictly speaking avidity since we were not working with monovalent antibodies) than the others (Butler et al., 1978). The amount of xanthan introduced to each polystyrene ELISA well was relatively high $\left(20 \mu \mathrm{g} \mathrm{ml}^{-1}\right)$, thus favouring a non-affinity-dependent assay (Griswold, 1987). However, neither the coating efficiency of xanthan to immunoplates nor the subsequent available epitope density on adsorbed material was determined. When a molecule such as 
Table 3. Compiled competition data using various xanthans as competitor in tests with monoclonal antibodies

All entries are arithmetic means (to the nearest integer for values $>1)$ of quantities $\left[\mu \mathrm{g}(200 \mu \mathrm{l})^{-1}\right]$ of inhibitor necessary for $50 \%$ reduction of antibody activity against native xanthan 646 . The range is given in parentheses for duplicate experiments (for triplicate experiments in the case of native 646 and BD9).

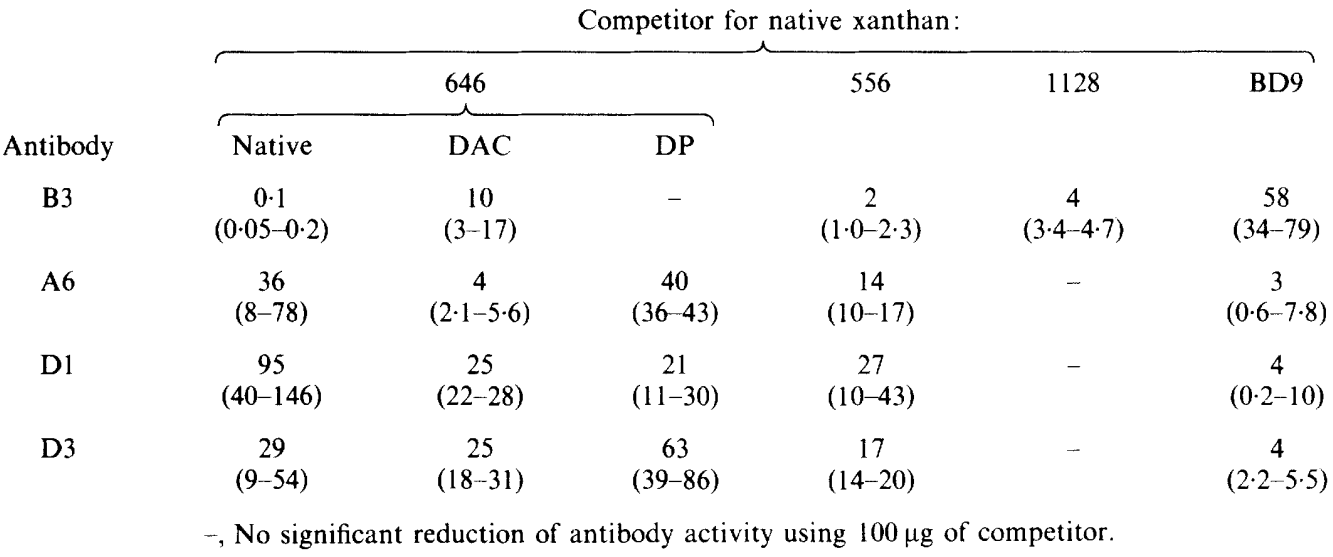

xanthan with a complex tertiary structure (reviewed by Rees et al., 1982) is passively adsorbed to a solid phase it may be that only a small fraction of epitopes will be accessible to antibodies. The different rates of antibody extinction could therefore indicate an affinity-dependent titration curve.

D3 was the only $\operatorname{lgG}$ monoclonal antibody $\left(\operatorname{lgG}_{2 \mathrm{~A}}\right)$, and it did not differ in behaviour from the IgM monoclonal antibodies in any way, suggesting that any possible isotype differences in performance could not account for the results obtained.

Monoclonal antibody B3. This monoclonal antibody consistently gave reactions unlike the others, being less reactive with the immunizing antigen, i.e. native 646 xanthan (Table 2). When chemically modified xanthan 646 was used as target, none of the monoclonal antibodies reacted with $646 \mathrm{DP}$, whereas they all gave good reaction with $646 \mathrm{DAC}$, with the exception of $\mathrm{B} 3$. This suggested that the pyruvate ketal on the terminal mannose is important for recognition by the $\mathrm{B} 3$ antibody.

When the other natural xanthan variants 556 and 1128 were used as targets, only B3 gave positive (but weak) reactions. The most striking finding was that B3 was the only antibody that could be inhibited by xanthan 1128 (Fig. 2, Table 3). This exopolysaccharide is poorly pyruvylated and more strongly acetylated than the native 646 xanthan. Also, the xanthan 556, which is highly pyruvylated and poorly acetylated, inhibited the B3 antibodies to approximately the same degree as 1128 . This would suggest that the specificity was against the fully acylated trisaccharide side-chain. Reactions with chemically modified xanthan 646 further indicated that the pyruvate ketal was more important than the acetylated inner mannose. This was further supported by the poorer blocking activity, relative to 646 , of the xanthan BD9, where most of the side-chains lack the terminal mannose.

The Klebsiella $\mathrm{K} 5$ polysaccharide possesses some structural similarity to xanthan (Jansson et al., 1975; van Dam et al., 1985), containing glucuronic acid and a 4,6 pyruvate ketal on mannose, but it failed to compete with xanthan 646 for antibodies except B3. Even this inhibition was weak, however $(69 \%$ residual antibody activity, Table 4$)$, using $100 \mu \mathrm{g}$ inhibitor. The inhibition profile approached horizontal once $40 \mu \mathrm{g}$ or more of inhibitor was employed. This pattern resembles a type 2 cross-reaction (Berzofsky \& Schechter, 1981), despite the fact that we were using monoclonal antibodies. The K5 polysaccharide apparently has a low affinity for the antibody which could not be compensated by using it at higher concentrations. This is likely since the $\mathrm{K} 5$ glucuronic acid residue is linked to a $2-\mathrm{O}$-acetylated glucose unit and thus differs 


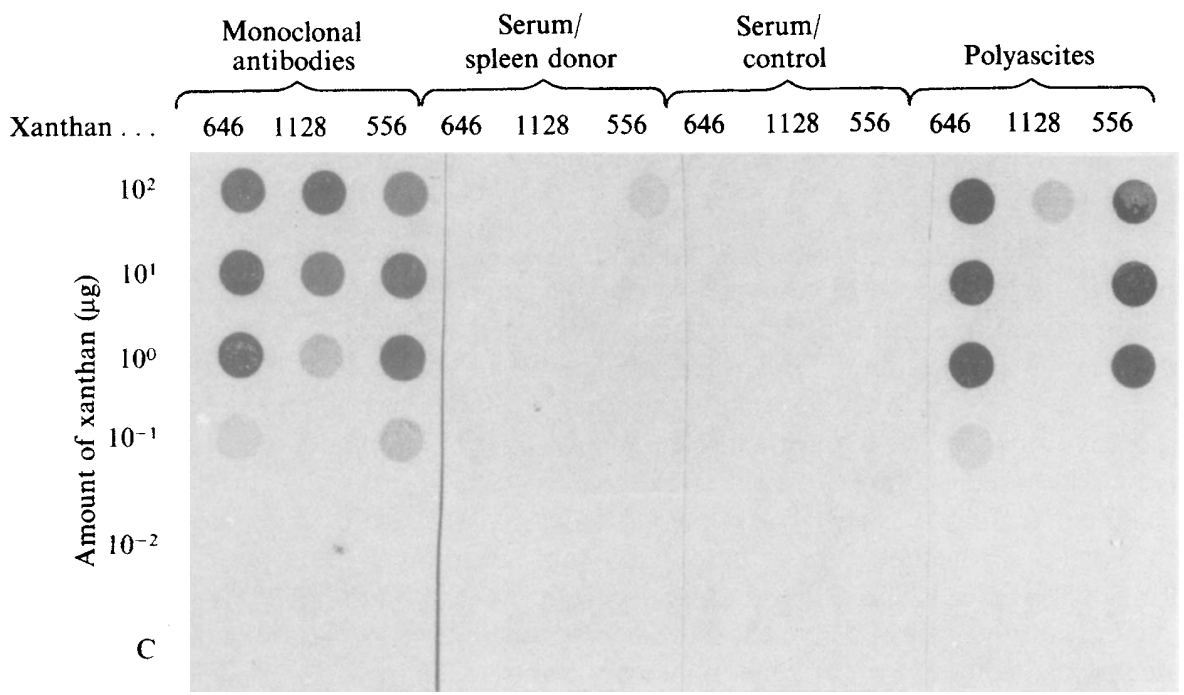

Fig. 3. Dot-blot assay on nitrocellulose paper using serial 10-fold dilutions of xanthans 646,1128 and 556 with PBS as control (C) probed with pooled cell culture supernatants of monoclonal antibodies, serum/spleen donor, serum/control, and polyascites. Antibodies were made up in PBS/T and used at dilutions giving an ELISA $A_{492}$ of $0.75-1.0$ according to the titration curve shown in Fig. 1, the exception being serum/control, which was employed at $1: 100$ dilution.

Table 4. Competitive effect of A21 and K5 on binding of xanthan 646 by monoclonal antibodies

All entries with competitors are means of duplicate tests and are presented as percentage of residual antibody activity relative to control assays (PBS/T) with a range of $\pm 3-7$ percentage units. Four replicates of each uncompeted antibody assay $(100 \%)$ gave a range of $\pm 8-11$ percentage units.

\begin{tabular}{|c|c|c|c|c|c|c|}
\hline & & & & & & \\
\hline & & 21 & & & 65 & \\
\hline & Con & $(200$ & & Cor & $(200$ & \\
\hline Antibody & 100 & 40 & 10 & 100 & 40 & 10 \\
\hline B3 & 61 & 81 & 99 & 69 & 70 & 97 \\
\hline A6 & 105 & 101 & 104 & 102 & 100 & 102 \\
\hline D1 & 103 & 99 & 102 & 100 & 101 & 100 \\
\hline D3 & 101 & 101 & 100 & 99 & 106 & 99 \\
\hline
\end{tabular}

* A21, the endo- $\beta$-glucosidase and lyase enzymic fragment of xanthan 646 ; K5, the Klebsiella $\mathrm{K} 5$ polysaccharide (see Methods).

from the xanthan structure. It was not possible, however, to resolve whether it was the pyruvylated mannose, the glucuronic acid or both that contributed to this reaction.

Unexpectedly, the oligosaccharide A21, generated from xanthan 646 by endo- $\beta$-glucosidase and lyase treatment, was a slightly better, but still weak, competitor for binding of the B3 antibody (Table 4). This tetrasaccharide contains the xanthan repeat unit without the terminal mannose moiety; it terminates in an unsaturated uronic acid residue and has a deacetylated mannose (Sutherland, 1987). This could imply that the B3 epitope comprises parts of the branching-point and would also be consistent with the conclusion that the acetate on the inner mannose is less critical for B3 recognition than the pyruvate ketal.

The polyclonal antibodies. The polyascitic fluid and the serum from the spleen donor gave very similar patterns of reactivity as the monoclonal antibodies A6, D1 and D3. We had expected these polyclonal sources of antibodies to cover a wider range of specificities and show some reaction against cellulose. Particularly the polyascitic fluid, harvested approximately 3 weeks after the injection of the booster dose, would be expected to reflect the initial hybridoma 
repertoire. As the immune response to branched plant polysaccharides is mainly against branching points and side-chains (reviewed by Bishop \& Jennings, 1982), it may well be that the A6, D1 and D3 monoclonal antibodies, initially selected at random before any knowledge of their finer specificity was at hand, are directed against the most immunogenic parts of the xanthan molecule.

\section{Detection of xanthan by dot-blotting}

The native xanthans 646,1128 , and 556 were adsorbed to nitrocellulose in order to construct a simple semi-quantitative immunodetection assay. The results (Fig. 3) showed that only the pooled monoclonal antibodies and the polyascites seemed to work satisfactorily. Serum from the spleen donor only gave a weak reaction with xanthan 556 , whereas the murine control serum did not give positive signals. The experiment clearly showed that quantities of approximately $0.1 \mu \mathrm{g}$ xanthan in a processed volume of $200 \mu \mathrm{l}$ could be detected. The xanthan 1128 was not so easily detected as the 646 and 556 types. The pooled monoclonal antibodies gave stronger signals with 1128 than did the polyascites, which may have been due to the B3 component of the mixture. The binding of 556 and 1128 to nitrocellulose differed from that to the polystyrene immunoplate, as the polyascitic fluid did not give an ELISA reaction with 556. These results underline the importance of choosing the right solid phase for xanthan studies.

As the dot-blot technique involves application of the sample by filtration, it would be possible to accommodate larger volumes in order to detect more dilute concentrations of xanthan material, except where nitrocellulose binding sites are blocked by impurities in the sample.

We thank Ms Litta Olsen for her skilful technical assistance.

\section{REFERENCES}

Berzofsky, J. A. \& Schechter, A. N. (1981). The concepts of crossreactivity and specificity in immunology. Molecular Immunology 18, 751-763.

Bishop, C. T. \& JENNINGS, H. J. (1982). Immunology of polysaccharides. In The Polysaccharides, vol. 1, pp. 291-330. Edited by G. O. Aspinall. New York \& London: Academic Press.

Butler, J. E., Feldbush, T. L., McGivern, P. L. \& STEWART, N. (1978). The enzyme-linked immunosorbent assay (ELISA): a measure of antibody concentration or affinity? Immunochemistry 15, 131136.

van Dam, J. E. G., van Halbeek, H., Kamerling, J. P., Vliegenhart, J. F. G., Snippe, H., Jansze, M. \& WILLERS, J. M. N. (1985). A bacteriophage-associated lyase acting on Klebsiella serotype 5 capsular polysaccharide. Carbohydrate Research 142, 338343.

Galfré, G., Howe, S. C., Milstein, C., Butcher, G. W. \& Howard, J. C. (1977). Antibodies to major histocompatibility antigens produced by hybrid cell lines. Nature, London 266, 550-552.

GRISWOLD, W. R. (1987). Theoretical analysis of the sensitivity of the solid phase antibody assay (ELISA). Molecular Immunology 24, 1291-1294.

HaAheim, L. R. \& Lund, H. (1984). Monoclonal antibodies to the $\mathrm{h}_{1}$ agglutinogen from Staphylococcus aureus 17A. Serological testing with type strains. Acta pathologica, microbiologica et immunologica scandinavica B92, 325-330.

Jansson, P.-E., Kenne, L. \& Lindberg, B. (1975). Structure of the extracellular polysaccharide from Xanthomonas campestris. Carbohydrate Research 45 , 275-282.

KenNedy, A. F. D. \& Sutherland, I. W. (1987). Analysis of bacterial exopolysaccharides. Biotechnology and Applied Biochemistry 9, 12-19.
LACY, M. J. \& Voss, E. W., JR (1986). A modified method to induce polyclonal ascites fluid in BALB/c mice using SP2/0-Ag14 cells. Journal of Immunological Methods 87, 169-177.

Rees, D. A., Morris, E. R., Thom, D. \& Madden, J. K. (1982). Shapes and interactions of carbohydrate chains. In The Polysaccharides, vol. 1, pp. 195290. Edited by G. O. Aspinall. New York \& London: Academic Press.

SANDFORD, P. A. \& BAIRD, J. (1983). Industrial utilization of polysaccharides. In The Polysaccharides, vol. 2, pp. 411-490. Edited by G. O. Aspinall. New York \& London: Academic Press.

Sutherland, I. W. (1982). An enzyme system hydrolysing the polysaccharides of Xanthomonas species. Journal of Applied Bacteriology 53, 385-393.

Sutherland, I. W. (1984). Hydrolysis of unordered xanthan in solution by fungal cellulases. Carbohydrate Research 131, 93-104.

SUTHERLAND, I. W. (1987). Xanthan lyases - novel enzymes found in various bacterial species. Journal of General Microbiology 133, 3129-3134.

Sutherland, I. W. \& Ellwood, D. C. (1979). Microbial exopolysaccharides - industrial polymers of current and future potential. Symposia of the Society for General Microbiology 20, 107-150.

Sutherland, I. W. \& Wilkinson, J. F. (1965). Depolymerases for bacterial exopolysaccharides obtained from phage-infected bacteria. Journal of General Microbiology 39, 373-383.

Yano, T., Pestana de Castro, A. F., Lauritis, J. A. \& NAMEKATA, T. (1979). Serological differentiation of bacteria belonging to the Xanthomonas campestris group by indirect hemagglutination test. Annals of the Phytopathological Society of Japan 45, 1-8. 